\title{
Intransitive aggregated preferences
}

Citation for published version (APA):

Storcken, A. J. A. (1996). Intransitive aggregated preferences. METEOR, Maastricht University School of Business and Economics. METEOR Research Memorandum No. 023 https://doi.org/10.26481/umamet.1996023

Document status and date:

Published: 01/01/1996

DOI:

10.26481/umamet.1996023

Document Version:

Publisher's PDF, also known as Version of record

\section{Please check the document version of this publication:}

- A submitted manuscript is the version of the article upon submission and before peer-review. There can be important differences between the submitted version and the official published version of record.

People interested in the research are advised to contact the author for the final version of the publication, or visit the DOI to the publisher's website.

- The final author version and the galley proof are versions of the publication after peer review.

- The final published version features the final layout of the paper including the volume, issue and page numbers.

Link to publication

\footnotetext{
General rights rights.

- You may freely distribute the URL identifying the publication in the public portal. please follow below link for the End User Agreement:

www.umlib.nl/taverne-license

Take down policy

If you believe that this document breaches copyright please contact us at:

repository@maastrichtuniversity.nl

providing details and we will investigate your claim.
}

Copyright and moral rights for the publications made accessible in the public portal are retained by the authors and/or other copyright owners and it is a condition of accessing publications that users recognise and abide by the legal requirements associated with these

- Users may download and print one copy of any publication from the public portal for the purpose of private study or research.

- You may not further distribute the material or use it for any profit-making activity or commercial gain

If the publication is distributed under the terms of Article $25 \mathrm{fa}$ of the Dutch Copyright Act, indicated by the "Taverne" license above, 


\section{INTRANSITIVE AGGREGATED PREFERENCES}

Ton Storcken ${ }^{1}$

June 1996

\section{ABSTRACT}

An impossibility theorem for preference aggretating rules is discussed. In this theorem no transitivity condition or acyclicity condition is imposed on the preferences: neither on the individual level nor on the aggregated level. Under the conditions that aggregation is non-dictatorial, Pareto-optimal, neutral and independent of irrelevant alternatives, it follows that the aggregated preferences are much more complex and therefore less ordered than the individual preferences.

1 Department of Quantitative Economics, Limburg University, P.O. Box 616, 6200 MD Maastricht 


\section{§1. Aggregated Preferences}

In Social Choice Theory the aggregated preferences of a society are often imposed by transitivity and/or acyclicity conditions. See e.g. Arrow [1963], Blair \& Pollack [1979], Blau [1957], Ferejohn \& Grether [1974], and many others. On the other hand Condorcet [1785] and Dodgson [1876], (see Black [1987]) studied aggregated preferences in which cycles may occur.

Since Arrow's impossibility theorem which implies that dictatorial rules are the only preference aggregation rules that are Pareto-optimal and independent of irrelevant alternatives, many variations of this theorem have been found. A great deal of these variations involve different transitivity conditions, hence different types of preference orderings. Therefore, this paper focusses on whether it is possible to get rid of these strongly negative results by dropping all transitivity and acyclicity conditions. Of course the aggregated preferences should express a kind of ordering, therefore it is imposed that the range of these mechanisms satisfies some ordering conditions. So, to answer this problem it is necessary to reconsider the range of aggregation mechanism. This range is often supposed to be the set of linear orderings, the set of weak orderings, the set of quasi-orderings, the set of semi-orderings, the set of interval orderings or the set of acyclic orderings (relations). In the description of these orderings the transitivity conditions are of vital importance and if these transitivity conditions are dropped, then of course the question arises which criteria to determine on ordering should be used. Any transitivity condition is too demanding. It excludes e.g., tournaments relations which have considered to be aggregated preferences. Furthermore, which transitivity conditions should be used and why?

In Swart \& Storcken [1992] the reader may find a fundamental treatment of the phenomenon ordering which is exploited here. As in their paper here also a set of relations which satisfies six specific conditions is said to be a set of orderings. These six conditions are:

! non-triviality meaning that the set of relation is neither empty nor contains all possible relations,

! closedness under permutation meaning that renaming alternatives has no effect on the orderedness, 
! closedness under reversion meaning that reversing all preference pairs has no effect on the orderedness,

! closedness under restriction meaning that parts of an ordering are ordered,

! closedness under concatenation meaning that ordering orderings in a linear way has no effect on the orderedness, and finally

! closedness under substitution means that the size of an indifference class or incomparability class in a relation has no effect on the orderedness.

All well-known sets of orderings satisfy these six criteria, but there are many other sets which do so as well. For instance the set of tournaments and many of its subsets satisfy these six conditions. So, although transitivity may give rise to a specific type of orderings in that framework it is no longer the main ingredient. Furthermore, because the last five conditions are based on operations, closure operations on sets can be defined. By these the smallest set of orderings containing a given set of relations can be determined. Therefore, a type of ordering can be regarded as an arrangement (according to the operations) of some admitted atomic pieces of disorder. This is stressed by the result that a minimal extension of a set of orderings is only acheaved by adding one new atomic piece of disorder. In section 2 this is explained with more details.

In section 3 by virtue of this system of ordering the aggregation of preference orderings is studied in a broader view. Actually aggregation rules which are Pareto-optimal, independent of irrelevant alternatives and neutral are studied. It appears that although the range of these mechanisms is no longer imposed by transitivity conditions, contamination with serious defects remains prominent. Let for instance both the set of individual orderings and the range of the aggregation rule be subsets of the set of tournaments. Then theorem 3.2 implies that the rule is either dictatorial or its range consists of infinitely many more atomic pieces of disorder than the set of individual orderings does. By Pareto-optimality this latter set is contained in that range. Therefore, one could say that avoiding dictatorship implies a non-marginal admittance of new atomic pieces of disorder, which of course makes the aggregated outcomes much more complicated. In other well-known impossibility theorems, see e.g. Arrow [1963], Blair \& Pollack [1979], Blau [1979], Ferejohn \& Grether [1974] and many others, the aggregation rules are not imposed by neutrality. So, the new result presented here suggests that there is a certain trated-off between neutrality and the transitivity of the 
orderings in the range. Moreover, in Storcken [1989] it is shown that under very mild transitivity conditions for the orderings in the range, Pareto-optimality non-dictatorship and independence of irrelevant alternatives imply neutrality. 


\section{$\S 2$. ORDERINGS}

The system, introduced hereafter, classifies sets of relations as sets of orderings. The classification is done by six critiria for sets of relations. So, the system classifies types of orderings. The type of ordering, e.g. linearity, weakness, seminess, intervalness or quasiness, of a given relation is determined by the classified set of orderings which that relation is an element of. To be clear a relation can have several types, e.g. a linear ordering can also be a weak ordering.

Altough only finite sets of alternatives are taken into consideration, the classification does not depend on the number of elements which should be ordered. Therefore to be able to discuss relations on a domain with an arbitrary number of elements, an infinite but countable set of possible alternatives is needed. Let $\mathbf{U}$ be this infinite countable set. Now $\mathbf{D}:=\{X * X \phi \mathbf{U}, \mathbf{X} \quad \imath$ and $X$ is infinite $\}$ is the set of all finite and non-empty subsets of $\mathbf{U}$. $\mathbf{D}$ is the set of all possible domains of the relations discussed hereafter. Furthermore, $\mathbf{R}:=\left\{<R, A>{ }^{*} A 0 \mathbf{D}\right.$ and $\left.R \phi A \times A\right\}$ is the set of possible relations coupled with their domains. The explicit denotation of the domains is necessary because later on operations are defined that change the domain of a relation. Instead of $<R, A>$ also $R_{A}$ is written. The last given set for the classification system is $S_{U}$ the set of all permutations on $\mathbf{U}$.

In the following definition several monadic and binary operators are introduced. Some of these are well-known but denoted accordingly to denotations used here instead of standard notations in literature.

\section{DEFINITION 2.1 Relation Operators}

Let $R_{A}$, $R_{B}^{\prime}$ be two relations in $\mathbf{R}$. Let a $0 A$ and let $\Phi 0 S_{U}$. Let $D \phi A$ such that $D \quad$.

2.1.0 $c R_{A}:=\left\langle\left\{<x, y>*<x, y>\int R_{A}\right\}, A>\right.$ is the complement of $R_{A}$.

2.1.1 $a R_{A}:=<\left\{<x, y>0 R_{A}{ }^{*}<y, x>\int R_{A}\right\}, A>$ is the asymmetric part of $R_{A}$.

2.1.2 $\mathrm{sR}_{\mathrm{A}}:=<\left\{<x, y>0 \mathrm{R}_{\mathrm{A}}{ }^{*}<y, x>0 \mathrm{R}_{A}\right\}$, $A>$ is the symmetric part of $\mathrm{R}_{\mathrm{A}}$.

2.1.3 $v R_{A}:=\left\langle\left\{<x, y>{ }^{*}<y, x>0 R_{A}\right\}, A>\right.$ is the reverse of $R_{A}$.

2.1.4 $\Phi R_{A}=<\left\{<\Phi(x), \Phi(y)>0 \Phi(A) \times \Phi(A):<x, y>0 R_{A}\right\}, \Phi(A)>$, is the $\Phi$ permutation of $R_{A}$

2.1.5 $R_{A}{ }^{*} D:=<\left\{<x, y>0 D \times D *<x, y>0 R_{A}\right\}, D>$ is the restriction of $R_{A}$ to $D$.

2.1.6 Let $A 1 B=1 . R_{A}+R_{B}^{\prime}:=<\left\{<x, y>{ }^{*}<x, y>0 R_{A},<x, y>0 B_{B}^{\prime}\right.$ or $\left.<x, y>0 A \times B\right\}$, 
$A \chi B>$ is the concatenation of $R_{A}$ with $R_{B}^{\prime}$.

2.1.7 Let furthermore, $A \perp B \phi\{a\}$ and $Z=(A-\{a\}) \chi B$. Sub $\left(R_{A}, a, R_{B}^{\prime}\right):=<\{<x, y>$ * $<x, y>0 R_{B}^{\prime},<x, y>0 R_{A^{*}-\{a\}}$, $x 0 B$ and $<a, y>0 R_{A}$, or y $0 B$ and $\left.<x, a>0 R_{A}\right\}, Z>$ is the substitution of $R_{B}^{\prime}$ on a in $R_{A}$.

In $R_{A}+R_{B}^{\prime}$ all the elements in $A$ are strictly preferred to all the elements of $B$, where $R_{A}$ $+R_{B}^{\prime}$ and $R_{A}$ are the same on $A$ and $R_{A}+R_{B}^{\prime}$ is equal to $R_{B}^{\prime}$ on $B$. So, $(A \times B)_{A X B} \phi a\left(R_{A}\right.$ $\left.+R_{B}^{\prime}\right),\left(R_{A}+R_{B}^{\prime}\right)^{\star}{ }_{A}=R_{A}$ and $\left(R_{A}+R_{B}^{\prime}\right)^{\star}{ }_{B}=R_{B}^{\prime}$. In Sub $\left(R_{A}, a, R_{B}^{\prime}\right) R_{B}^{\prime}$ plays the rôle of a in $\mathrm{R}_{\mathrm{A}}$.

Next the definition of orderings is introduced.

\section{DEFINITION $2.2 \quad$ Orderings}

Let $\mathrm{V} \delta \mathbf{R}$ a set of relations.

$V$ is classified as a set of orderings, iff

2.2.1 $V$ is closed under permutation, i.e., $\quad \Phi R_{A} 0 \mathrm{~V}$, for all $\Phi 0 S_{U}$ and all $R_{A} 0 V$,

2.2.2 $V$ is closed under reversion, i.e., $v R_{A} 0 V$, for all $R_{A} 0 V$,

2.2.3. $V$ is closed under restriction, i.e., $\quad R_{A}{ }^{*} B V$, for all $R_{A} 0 V$ and all $1 \quad B \phi A$,

2.2.4 $V$ is closed under concatenation, i.e., $R_{A}+R_{B}^{\prime} 0 V$, for all $R_{A}, R_{B}^{\prime} 0 \vee$ with $A 1 B=$ 1 ,

2.2.5 $V$ is non-trivial, i.e., $\quad$ for all $X 0 \mathbf{D}$ there are $R_{X}, R_{X}^{\prime} 0 \mathbf{R}$ such that $R_{X} 0 \vee$ and $\mathrm{R}_{\mathrm{x}}^{\prime} \Gamma \mathrm{V}$, and

2.2.6 $V$ is closed under substitution, i.e., $\operatorname{Sub}\left(R_{A}, a, R_{B}^{\prime}\right) 0 V$, for all a $0 A$ and all $R_{A}, R_{B}^{\prime}$ $0 \mathrm{~V}$, with $v \mathrm{R}_{\mathrm{B}}^{\prime}=\mathrm{R}_{\mathrm{B}}^{\prime}$ and $\mathrm{A} 1 \mathrm{~B} \phi\{\mathrm{a}\}$.

If $\mathrm{V} \phi \mathbf{R}$ is classified as set of orderings, then $\mathrm{V}$ is closed under 5 operations and nontrivial. If $\mathrm{V}$ is closed under permutation, then $\mathrm{V}$ does not discreminate between the names of the elements of $\mathbf{U}$. The closedness under reversion implies that if $R_{A}$ is a special type or ordering, then the relation $v R_{A}$ where every element is ordered in a reversed way is also of that type. The closedness under restriction implies that parts of a special type of ordering are also of that type. The closedness under concatenation 
implies that it is possible to order orderings of a special type in a linear way. The closedness under substitution implies that reversible parts of a relation can be substituted by reversible relations. The non-triviality implies that on every possible domain $\mathbf{X} 0 \mathbf{D}$ a classified set is a non-trivial set of relations. By this it is clear that the six conditions 2.2.1 up to 2.2.6 are very natural.

In Swart \& Storcken [1992] it is proved that all well-known sets of orderings, such as the set of linear orderings $\mathbf{L}:=\left\{R_{X} 0 \mathbf{R}\right.$ : $\mathbf{R}_{\mathbf{X}}$ is reflexive, complete, antisymmetric and transitive\}, are all classifiable as sets of orderings. But also new types of orderings are found, e.g., for integers $m, p>0$

$\mathbf{T}_{m, p}:=\left\{R_{X} 0 \mathbf{R} * \quad R_{X}\right.$ is reflexive, antisymmetric and complete and there are a partition $\mathrm{X} 1, \mathrm{X} 2, \ldots, \mathrm{Xk}$ of $\mathrm{X}$ and relations $\mathrm{R} 1_{\mathrm{X} 1}, \mathrm{R} 2_{\mathrm{X} 2}, \ldots \mathrm{Rk} \mathrm{xk}_{\mathrm{K}}$ such that

(1) $R 1_{x 1}+R 2_{x 2}+\ldots+R k_{x k}=R_{x}$,

(2) ${ }^{\star} \mathrm{Xi} * \# \mathrm{~m}$ for all i $0\{1, \ldots, \mathrm{k}\}$,

(3) for all $\mathrm{Ri}_{\mathrm{X}_{\mathrm{i}}}$ there are $\mathrm{Li}_{\mathrm{x}_{\mathrm{i}}} 0 \mathrm{~L}$ such that $\left.*\left(\mathrm{Ri}_{\mathrm{x}_{\mathrm{i}}}, \mathrm{Li}_{\mathrm{x}_{\mathrm{i}}}\right) \# \mathrm{p}\right\}$.

Here $*$ denotes the Kemeny distance between two relations $\left.*\left(R_{X}, R_{X}^{\prime}\right):=1 / 2^{\star} R_{X}\right) R_{X}^{\prime}$. See also Kemeny \& Snell [1962]. Distance function $*$ on relations counts the preference pairs which have to be reversed to obtain relations $R_{x}$ from $R_{x}^{\prime} \cdot \mathbf{T}_{m, k}$ consists of those tournaments in $\mathbf{T}:=\left\{\mathrm{R}_{\mathrm{X}} 0 \mathbf{R}: \mathrm{R}_{\mathrm{X}}\right.$ is reflexive, complete and antisymmetric $\}$ in which there are no circuits of length greater than $m$ and the circuits of length smaller or equal to $m$ are at most on distance $\mathrm{k}$ from $\mathbf{L}$. In the classification system along with the well-known sets of orderings an infinite number of new sets of orderings are found. 
Diagram of elements of $\mathbf{T}_{5,3}$

Having this classification system of orderings, it is possible to deduce several properties about sets of orderings. Such that if $\mathrm{V}$ is classified as a set of orderings, then all relations in $\mathrm{V}$ are reflexive or all relations in $\mathrm{V}$ are irreflexive. Or every classified set of orderings $\mathrm{V}$ has a subset $\mathrm{W}$ which is order isomorph to the set of linear orderings. So, there is nothing "more ordered" than linearly. A well-known consequence of this theorem is $\mathbf{L} \phi \mathbf{W}:=\left\{R_{x} 0 \mathbf{R},: R_{x}\right.$ is reflexive, complete and transitive $\}$, where $\mathbf{W}$ is the set of weak orderings.

It is obvious that $\mathbf{L} \mathbf{W}$. So, $\mathbf{L} \delta \mathbf{W}$. A question is now whether or not there is a set $\mathbf{V}$ $\phi \mathbf{R}$ which is a classified set of orderings such that $\mathbf{L} \delta \vee \delta \mathbf{W}$ ? Or formulated otherwise: Is $\mathbf{W}$ a minimal extension of $\mathbf{L}$ ? Because this notion of minimal extension is important later on in this paper it is introduced more precise.

\section{DEFINITION 2.3 Minimal Extension}

Let $\mathrm{V}, \mathrm{W} \phi \mathbf{R}$ be two sets of orderings.

$\mathrm{W}$ is a minimal extension of $\mathrm{V}$, iff $\mathrm{V} \delta \mathrm{W}$ and for all classified sets of orderings $\mathrm{X}$ not $\mathrm{V} \delta \mathrm{X} \delta \mathrm{W}$. Notation $\mathrm{V} \delta_{\mathrm{m}} \mathrm{W}$.

Now the greater a classified set of orderings is, the more atomic pieces of disorder in an ordering are admitted, the less structured the orderings in that set can be. So, a minimal extension, $\mathrm{V} \delta_{\mathrm{m}} \mathrm{W}$, is a minimal loss of structure in ordering elements.

In order to discuss the impossibility theorems developed in the following section it is necessary to characterize this notion of minimal extension. Therefore some closuring operations are defined. 


\section{DEFINITION $2.4 \quad$ Closure}

Let $\mathrm{V} \phi \mathbf{R}$ be a set of relations.

2.4.1 $\quad \mathrm{E}_{1}(\mathrm{~V})$ is the closure under permutation of $V$, i.e.

$\mathrm{E}_{1}(\mathrm{~V}):=1\{\mathrm{~W} \phi \mathbf{R}: \mathrm{V} \phi \mathrm{W}$ and $\mathrm{W}$ is closed under permutation $\}$.

2.4.2 $\quad E_{2}(V)$ is the closure under reversion of $V$, i.e.

$\mathrm{E}_{2}(\mathrm{~V}):=1\{\mathrm{~W} \phi \mathbf{R}: \mathrm{V} \phi \mathrm{W}$ and $\mathrm{W}$ is closed under reversion $\}$.

2.4.3 $\quad E_{3}(V)$ is the closure under restriction of $V$, i.e.

$\mathrm{E}_{3}(\mathrm{~V}):=1\{\mathrm{~W} \phi \mathbf{R}: \mathrm{V} \phi \mathrm{W}$ and $\mathrm{W}$ is closed under restriction $\}$.

2.4.4 $\quad \mathrm{E}_{4}(\mathrm{~V})$ is the closure under concatenation of $\mathrm{V}$, i.e.

$\mathrm{E}_{4}(\mathrm{~V}):=1\{\mathrm{~W} \phi \mathbf{R}: \mathrm{V} \phi \mathrm{W}$ and $\mathrm{W}$ is closed under concatenation $\}$.

2.4.5 $\quad E_{5}(V)$ is the closure under substitution of $V$, i.e.

$\mathrm{E}_{5}(\mathrm{~V}):=1\{\mathrm{~W} \phi \mathbf{R}: \mathrm{V} \phi \mathrm{W}$ and $\mathrm{W}$ is closed under substitution $\}$.

A closure operation assigns to an arbitrary set $\mathrm{V} \phi \mathbf{R}$ a set $\mathrm{W} \phi \mathbf{R}$ which is closed under a specific operation and contains $\mathrm{V}$, such that $\mathrm{W}$ is the "smallest" set satisfying those two conditions. If for instance $\mathrm{V}$ can be classified as a set of orderings, then $\mathrm{E}^{\mathrm{i}}(\mathrm{V})=\mathrm{V}$ for all i $0\{1,2,3,4,5\}$.

The following theorem characterizes minimal extensions.

\section{THEOREM 2.5 Character of minimal extensions}

Let $\mathrm{V}$ and $\mathrm{W}$ be two classified sets of orderings. Then (2.5.1) and (2.5.2) are equivalent.

\subsection{1 $\vee \delta_{\mathrm{m}} \mathrm{W}$.}

2.5.2 There exists a relation $R_{X} 0 \mathrm{~W}-\mathrm{V}$, such that

2.5.2.1 $R_{X}{ }^{*} Y 0$ for all $1 \quad Y \delta X$

2.5.2.2 $\mathrm{M}(\mathrm{V}):=\mathrm{E}_{4} \mathrm{E}_{5} \mathrm{E}_{3} \mathrm{E}_{2} \mathrm{E}_{1}\left(\mathrm{~V} \chi\left\{\mathrm{R}_{\mathrm{X}}\right\}\right)=\mathrm{E}_{4} \mathrm{E}_{5}\left(\mathrm{~V} \chi\left\{\mathrm{R}_{\mathrm{X}}, \mathrm{vR}\right\}\right)=\mathrm{W}$.

\section{PROOF OF THEOREM 2.5}

See Swart \& Storcken [1992].

Theorem 2.5 characterizes minimal extensions: $V \delta_{m} W$ iff there is a relation $R_{x} 0 W-V$, 
such that the "smallest" classifiable set of orderings which contains $V \chi\left\{R_{x}\right\}$ is equal to $W$. So, $W$ is obtained by adding one new type of (dis)order, $R_{x}$, to $V$. Therefore, every relation $R_{A} 0 \mathrm{~W}$ can be constructed, i.e., by permutation, reversion, restriction, concatenation or substitution, from the relations in $V$ and one additional relation $R_{x}$.

Suppose $W_{0} \delta_{m} W_{1} \delta_{m} W_{2} \delta_{m} \ldots \delta_{m} W_{k}$ for classifiable sets of orderings $W_{0}, W_{1}, \ldots \ldots W_{k}$. Then by theorem 2.5 there are $R 1_{x 1}, R 2_{x_{2}}, \ldots, R k_{x k}$ such that $R i_{x_{i}} 0 W_{i}-W_{-1}$ and $W=$ $M\left(W_{i-1} \chi\left\{R_{i}\right\}\right)$. So, every relation $R_{A} 0 W_{k}$ can be constructed from the relations in $W_{0}$ and a finite number of additional relations. Or stated otherwise only a finite number of new types of (dis)order has to be added to $W_{0}$ in order to obtain $W_{k}$. This notion is important in the following section.

The following lemmas 2.6 and 2.7 are used in section 3. A relation $R_{x} 0 \mathbf{T}$ is reducible iff there exists a non-trivial subset $A$ of $X$ such that $R_{X}=R_{X}^{*}+R_{X}^{*}{ }_{x}^{*}$. Let $\mathbf{C}:=$ $\left\{R_{X} 0 \mathbf{R} * R_{X}\right.$ is reflexive and complete $\}$ be the set of strongly complete relations. It can be classified as a set of orderings. For all $R_{X} 0 C$ an equivalence relation $E\left(R_{X}\right)$ on $X$ is defined for all a,b $0 X$ as follows. The pair $<a, b>$ is in $E\left(R_{x}\right)$ if for all $x 0 X\left[<a, x>0 R_{x}\right.$ ] $<b, x>0 R_{x}$ and $\left.<x, a>0 R_{x}\right]<x, b>0 R_{x}$ ]. So, $<a, b>0 E\left(R_{x}\right)$ iff they are related to all elements in $X$ similarly. A relation $R_{X} 0 \mathbf{C}$ cannot be condensated iff all equivalence classes of $E\left(R_{X}\right)$ are singletons. Note that if $R_{X}$ cannot be condensated, then there are no relations $R_{A}, R_{B}^{\prime} 0 \mathbf{C}$ and elements a $0 A$ such that $v R_{B}^{\prime}=R_{B},{ }^{\star} B^{\star} \exists 2, A 1 B=1$ and $R_{X}=\operatorname{Sub}\left(R_{A}, a, R_{B}^{\prime}\right)$.

\section{LEMMA 2.6}

Let $V, W \phi \mathbf{C}$ be classified sets of orderings such that $V \delta_{m} W$. Let $R_{x} 0 W$ be irreducible and suppose it cannot be condensated. Then for all $1 \quad Y \delta X: R_{X}{ }^{*} Y 0 V$.

\section{PROOF OF LEMMA 2.6}

Let $R_{X} 0 \mathrm{~W}-\mathrm{V}$ be irreducible and suppose it cannot be condensated. Take $\imath \mathrm{Y} \delta \mathrm{X}$. Now by theorem $2.5 \mathrm{R}_{X} 0 \mathrm{~W}=\mathrm{E}_{4} \mathrm{E}_{5} \mathrm{E}_{3} \mathrm{E}_{2} \mathrm{E}_{1}\left(\mathrm{~V} \chi\left\{\mathrm{R}_{A}^{\prime}\right\}\right)$ for some $\mathrm{R}_{A}^{\prime} 0 \mathrm{~W}-\mathrm{V}$ such that for all 1 B $\delta$ A: $R_{A}^{\prime *}{ }_{B} 0 V$. Because $R$ is irreducible $R 0_{5} E_{3} E_{2} E_{1} E\left(V \chi_{A}\left\{R^{\prime}\right\}\right)$. Because $R$ cannot be condensated $R_{X} 0 E_{3} E_{2} E_{1}\left(V \chi\left\{R^{\prime}\right\}\right)=V \chi E_{3} E E\left(\left\{R^{\prime}\right\}\right)$. But now it follows evidently that $R_{X}{ }^{*} Y 0$ V. 
Because all tournaments cannot be condensated it follows:

\section{LEMMA 2.7}

Let $\mathrm{V}, \mathrm{W} \phi \mathbf{T}$ be classified sets of orderings such that $\mathrm{V} \delta_{\mathrm{m}} \mathrm{W}$. Let $\mathrm{R}_{\mathrm{x}} 0 \mathrm{~W}$ be irreducible. Then for all $\mathrm{l} Y \delta X: R_{X}{ }^{*} Y 0$. 


\section{§ 3. AN IMPOSSIBILITY IN AGGREGATING INTRANSITIVE PREFERENCES}

In this section it will be proved that there is no "nice" aggregation rule, F, from a set of classified profiles $\mathrm{V}^{\mathrm{n}}$ (of a set of individuals $\mathrm{N}$ over a classified set of orderings $\mathrm{V} \phi \mathbf{T}$ ) to the set of tournaments $\mathbf{T}$, such that there exist classified sets of orderings $\mathrm{V}=\mathrm{W}_{0}$, $\mathrm{W}_{1}, \ldots, \mathrm{W}_{\mathrm{k}} \phi \mathbf{T}$ for any finite $\mathrm{k}$ with $\mathrm{W}_{0} \delta_{\mathrm{m}} \mathrm{W}_{1} \delta_{\mathrm{m}} \mathrm{W}_{2} \ldots \ldots \delta_{\mathrm{m}} \mathrm{W}_{\mathrm{k}}$ and $\mathrm{F}\left(\mathrm{V}^{\mathrm{n}}\right) \phi \mathrm{W}_{\mathrm{k}} \phi \mathbf{T}$. So, in order to have a "nice" aggregation rule $F$ it is necessary to admit infinitely many new types of (dis)order in the range of $F$. In that case compared to $V$ the range of $F$ is very much less structured.

First we define the notion used above and then we deduce this impossibility result.

Throughout this section let $\mathrm{V} \delta \mathrm{T}$ be a classified set of orderings and let $\mathrm{N}:=\{1,2, \ldots, \mathrm{n}\}$ a set of $n(\exists 1)$ individuals $V^{n}:=\left\{B_{A}: B_{A}=<R 1_{A}, R 2_{A}, \ldots, R n_{A}>\right.$ for some $R 1_{A}, R 2_{A}, \ldots, R n_{A}$ $0 \mathrm{~V}$ \} is the set of profiles of $N$ over $\mathrm{V}$. If $\mathrm{B}_{\mathrm{A}} 0 \mathrm{~V}^{\mathrm{n}}$ and $\mathrm{i} 0 \mathrm{~N}$, then $\mathrm{B}_{A}(i)$ is the $i^{\text {th }}$ component of $B_{A}$, hence $R_{A}=B_{A}(i)$. It is the relation of individual $i$ at profile $B_{A}$.

Now let $\mathrm{W} \phi \mathbf{R}$ be a classified set of orderings and throughout this section let $\mathrm{F}$ be a function from $V^{n}$ to $W . F$ is called a welfare function or aggregation rule. Suppose further throughout this section, that $F$ has the following 3 properties:

$F$ is Pareto-optimal, i.e. $F\left(<R_{A}, R_{A}, \ldots, R_{A}>\right)=R_{A}$, for all $R_{A} 0 V$, $\mathrm{F}$ is neutral, i.e. $\mathrm{F}\left(\Phi \mathrm{B}_{\mathrm{A}}\right)=\Phi \mathrm{F}\left(\mathrm{B}_{\mathrm{A}}\right)$, for all $\mathrm{B}_{\mathrm{A}} 0 \mathrm{~V}^{\mathrm{n}}$ and $\Phi 0 \mathrm{~S}_{\mathrm{U}}$, where $\Phi \mathrm{B}_{\mathrm{A}}(\mathrm{i})=$ $<\Phi B_{A}(1), \Phi B_{A}(2), \ldots, \Phi B_{A}(n)>$,

3) $\quad F$ is independent of irrelevant alternatives, i.e. for all $B_{A}, B_{A}^{\prime} 0 V^{n}$ and all $1 \quad B \phi$ A: if $B_{A}{ }_{B}{ }_{B}=B_{A}^{\prime \star}{ }_{B}$, then $F\left(B_{A}\right)_{B}^{\star}=F\left(B_{A}^{\prime}\right)_{B}^{\star}$, where $B_{A}^{\star}{ }_{B}^{\star}=<B_{A}(1)_{B}^{\star}, B_{A}(2)_{B}^{\star}, \ldots$, $B_{A}(n){ }_{B}>$.

These three properties are well-known in Social Choice Theory, see e.g., Sen [1986] or Kelly [1978]. It is straightforward to prove that:

\section{LEMMA 3.1}

If $F\left(V^{n}\right) \delta T$ or $V=L$, then $F\left(V^{n}\right)$ can be classified as a set of orderings.

See also Storcken [1989]. The following theorem formalizes the impossibility result 
indicated above.

\section{THEOREM 3.2}

Let $\mathrm{k}$ be an arbitrary number such that $\mathrm{V}=\mathrm{W}_{0}, \mathrm{~W}_{1}, \ldots, \mathrm{W}_{\mathrm{k}} \phi \mathbf{T}$ are classified sets of orderings. Furthermore, suppose $W_{0} \delta_{m} W_{1} \delta_{m} \ldots \delta_{m} W_{k}=F\left(V^{n}\right)$ and $V \quad T$. Then $F$ is dictatorial, i.e., there is an individual i $0 \mathrm{~N}$ such that for all $\mathrm{B}_{\mathrm{A}} 0 \mathrm{~V}^{\mathrm{n}}: \mathrm{B}_{\mathrm{A}}(\mathrm{i}) 1 \operatorname{avF}\left(\mathrm{B}_{\mathrm{A}}\right)=$

Theorem 3.2 implies that several "nice" conditions for welfare functions together imply dictatorship. In this sence theorem 3.2 can be interpreted as an other impossibility theorem. The novelty of theorem 3.2 is that the conditions on the range and domain of the welfare function are not in terms of transitivity or acyclicity. By virtue of the classification system of orderings it is possible to determine orderings without making use of transitivity conditions. Furthermore, it is possible to compare sets of orderings in terms of constructions. As we have formulated in $\S 2$ the domain-range condition imposes that elements in the range can be constructed from the elements of the domain and a finite number of additional types of (dis)order. The other conditions are often explicitly (Pareto-optimality and the independence of irrelevant alternatives) or implicitly (neutrality) imposed on welfare function. So, to resolve the traditional impossibility it is necessary to admit a range which contains infinitely many types of (dis)order which are not in the domain. In that case the domain, compared to the range, is much more structured.

To prove theorem 3.2 we assume (3.3) and deduce a contradiction by several lemma's.

\section{ASSUMPTION 3.3}

Let $k$ be a number such that $V=W_{0}, \ldots, F\left(V^{n}\right)=W_{k} \phi T$ be classified sets of orderings $\mathrm{V} T$ and $\mathrm{W}_{0} \delta_{\mathrm{m}} \mathrm{W}_{1} \delta_{\mathrm{m}} \mathrm{W}_{2} \delta_{\mathrm{m}} \ldots \delta_{\mathrm{m}} \mathrm{W}_{\mathrm{k}}$. Furthermore, let $\mathrm{F}$ be non-dictatorial, i.e., for all i $0 \mathrm{~N}$ there is a profile $B_{A} 0 V^{n}$ such that $B_{A}(i) 1 \operatorname{avF}\left(B_{A}\right)$.

The following lemma states that if a specific sequence of sets of orderings is in the range of $F$, then this sequence is also in the domain. 


\section{LEMMA $3.4 \quad$ (Assume 3.3).}

Let $p$ be a non-negative integer. If for all $m 0\{0,1,2, ..\} \mathbf{T}_{m, p} \phi F\left(V^{n}\right)$, then for all $m 0$ $\{0,1,2, ..\} \mathbf{T}_{\mathrm{m}, \mathrm{p}} \phi \mathrm{V}$.

\section{PROOF OF LEMMA 3.4}

Let $\mathbf{T}_{m, p} \phi F\left(V^{\eta}\right)$ for all $m 0\{0,1,2, \ldots\}$. Take $R_{x} 0 \mathbf{T}_{t, p}$. It is sufficient to prove that $R_{x} 0 V$. Without loss of generality suppose $R_{X}$ is irreducible and ${ }^{\star} X^{\star}=t$. Then there exists a Hamilton circuit $<\mathrm{y}_{1}, \mathrm{y}_{2}, \ldots, \mathrm{y}_{\mathrm{t}}, \mathrm{y}_{1}>$ along $\mathrm{R}$, i.e., $\left\{\mathrm{y}, \mathrm{y}_{\mathrm{p}} \ldots, \mathrm{y}\right\}=\mathrm{X},{ }^{\star} \mathrm{X}^{\star}=\mathrm{t}$ and $<\mathrm{y}_{1}, \mathrm{y}_{2}>,<\mathrm{y}_{2}, \mathrm{y}_{3}>\ldots,<\mathrm{y}_{\mathrm{t}}, \mathrm{y}_{1}>0 \mathrm{aR}$.

$$
\left.\left.\left.\mathrm{y}_{3} .\right) 1\right)>1\right) \cdot \mathrm{y}_{4}
$$

$\mathrm{y}_{2}$

$$
\left.\left.\left.\mathrm{y}_{1} .\right) 1\right)<1\right) \cdot \mathrm{y}_{\mathrm{t}}
$$

Because $R_{x} 0 T_{t, p}$, there is a relation $R_{x}^{1} 0 L$ such that $*(R, R)$. W . Without loss of generality suppose $<y_{1}, y_{2}>0 R_{X}^{1}$. Take $Y:=X \chi A$, where $X 1 A={ }_{1}\{y\},{ }^{\star} A^{\star}=k$ and $A=\left\{y_{1}, a_{1}, a_{2}, \ldots, a_{k}\right\}$. Now we contruct $R_{Y}^{2} 0 \mathbf{L}$ and $R_{Y}^{3} 0 T_{t+k, p}$ such that $*\left(R_{Y}^{3}, R_{Y}^{2}\right) \# p$. Take $R_{Y}^{2}:=\operatorname{Sub}\left(R_{X}^{1}, y_{1}, R_{A}^{4}\right)$, where $y_{1} a_{1} a_{2} a_{3} \ldots a_{k}: R_{A}^{4}\left(R_{A}^{4}\right.$ ranks $y_{1}$ best $a_{1}$ second best and so on $)$. Take $\mathrm{R}_{\mathrm{Y}}^{3} 0 \mathrm{~T}$ such that for all $\mathrm{c}, \mathrm{d} 0 \mathrm{Y}$ :

$<\mathrm{c}, \mathrm{d}>0 \mathrm{R}_{\mathrm{Y}}^{3}$ iff $\quad<\mathrm{c}, \mathrm{d}>0 \mathrm{R}_{\mathrm{X}}$, or $<\mathrm{c}, \mathrm{d}>0 \mathrm{R}_{\mathrm{A}}^{4}$, or

$$
\begin{aligned}
& <c, d>=<a_{i}, y_{j}>, a_{i} 0 A, y_{j} 0 X !\left\{y_{1}\right\} \text { and }<y_{1}, y_{j}>0 R_{Y}^{2} \text {, or } \\
& <c, d>=<y_{j}, a_{i}>, a_{i} 0 A, y_{j} 0 X !\left\{y_{1}\right\} \text { and }<y_{j}, y_{1}>0 R_{Y}^{2} .
\end{aligned}
$$

Now $R_{Y}^{3 \star}{ }_{x}=R_{X}$. Because $R_{Y}^{3}$ and $R_{Y}^{2}$ only differ on $X$ it follows that $*\left(R_{Y}^{3}, R_{Y}^{2}\right)=*\left(R_{Y}^{3 \star}{ }^{3}, R_{Y}^{2 \star} x\right)$

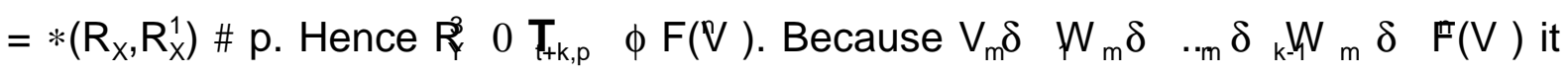
follows by repeated application of lemma 2.7 that $R_{Y}^{3{ }^{\star}}{ }_{x} 0 V$. Hence, $R_{x} 0 V$.

The following result is on decisiveness. Let $\mathrm{S} \phi \mathrm{N}$. Then $\mathrm{S}$ is said to be quasi-decisive if for all $x, y 0 U, x \quad y$, and all profiles $B_{A}$ $<x, y>0 B_{A}(i)$ for all i $0 S$ and $<y, x>0 B_{A}(j)$ for all $j 0 N$ ! S implies $<x, y>0$ aF $\left(B_{A}\right)$.

\section{LEMMA 3.5}

Assume (3.3). There are $\mathrm{S}, \mathrm{T}, \mathrm{M} \phi \mathrm{N}$ such that $\mathrm{S} 1 \mathrm{~T} 1 \mathrm{M}=\mathrm{l}$, all three are quasi-decisive 
and one of the following three (a), (b) or (c) holds. Where,

(a) $\mathrm{S} \chi \mathrm{T}=\mathrm{S} \chi \mathrm{M}=\mathrm{T} \chi \mathrm{M}=\mathrm{N}$;

(b) $\mathrm{S} 1 \mathrm{~T}=\mathrm{S} 1 \mathrm{M}=\mathrm{T} 1 \mathrm{M}=1$ and $\mathrm{S} \chi \mathrm{T} \chi \mathrm{M}=\mathrm{N}$;

(c) $\mathrm{S} \chi \mathrm{T} \delta \mathrm{M}, \mathrm{S} 1 \mathrm{~T}=1$ and $\mathrm{S} \chi \mathrm{T}$ is quasi decisive.

\section{PROOF OF LEMMA 3.5}

Let $\mathbf{B}$ be the set of quasi-decisive coalitions. Since $\mathrm{F}$ is non-dictatorial it follows that for all i $0 \mathrm{~N}$ there is a coalition $X_{i} 0 \mathbf{B}$ such that $i \int X_{i}$. Hence, $1\{X * X 0 B\}=1$. So, there are $X, Y 0 B$ such that $X 1 Y \cap B$. Obviously it follows that $Z=N !(X 1 Y) 0$ B. If $N$ ! $(X 1 Z) 0 B$, then take $S=X, M=Z$ and $T=N !(X 1 Z)$ and we are done by (a). So, X 1 Z 0 B. Similarly we are done if N ! (Y 1 Z) 0 B. So, Y 1 Z 0 B.

Take $S=X 1 Z$ and $T=Y 1 Z$. So, $X 1 Y=1$. If $S \chi T 0 B$, then $M=N 0 B$ because of Pareto-optimality and we are done by (c). So, $\mathrm{M}=\mathrm{N}$ ! (S $\chi \mathrm{T}) 0 \mathrm{~B}$ which yields case (b).

The following lemma is in some sense the reverse of lemma 3.4. If the sequence of sets of orderings $\mathbf{T}_{m, p}$ for $\mathrm{m} \exists 1$ is in the domain of $F$ then the sequence of sets of orderings $\mathbf{T}_{\mathrm{m}, \mathrm{p}+1}$ for $\mathrm{m} \exists 1$ is in the range of $\mathrm{F}$.

\section{LEMMA 3.6}

Assume (3.3). Let $p$ be a non-negative integer.

If for all $m 0\{0,1,2, \ldots\} \mathbf{T}_{m, p} \phi V$, then for all $m 0\{0,1,2, \ldots\} \mathbf{T}_{m, p+1} \phi F\left(V^{n}\right)$

\section{PROOF OF LEMMA 3.6}

Take t,p $0\{0,1,2, \ldots\}$ and suppose $\mathbf{T}_{m, p} \phi \vee$ for all $m 0\{0,1,2, \ldots\}$.

Let $R_{X} 0 T_{t, p+1}$. It is sufficient to prove that $R_{X} 0 F\left(V^{n}\right)$.

Without loss of generality suppose $R_{X}$ is irreducible and $R_{X} 0 T_{t, p+1}-T_{t, p}$.

Then there is a $R_{X}^{1} 0 L$ such that $*\left(R_{X}, R_{X}^{1}\right)=p+1 \exists 1$. Hence, there are $x, y 0 X$ such that $<\mathrm{x}, \mathrm{y}>0 \mathrm{R}_{\mathrm{x}}$ and $<\mathrm{y}, \mathrm{x}>0 \mathrm{R}_{\mathrm{x}}^{1}$.

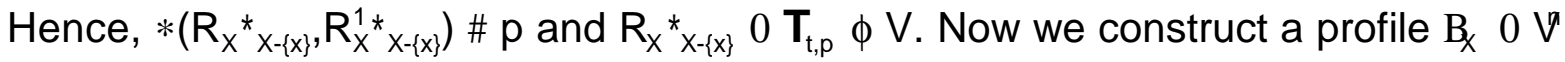
such that $F\left(B_{X}\right)=R_{X}$. 
By lemma 3.5 there are quasi-decisive $S, T, M$ such that $S 1 \mathrm{~T} 1 \mathrm{M}=1$. Let $X_{1}:=\{b 0$ $\left.X-\{x\}{ }^{*}<b, x>0 R_{x}\right\}$ and $X_{2}:=\left\{b 0 X-\{x\}{ }^{*}<x, b>0 R_{x}\right\}$. Since $R_{x}$ is irreducible $X \quad 1$ and $X_{2}$ l. Therefore

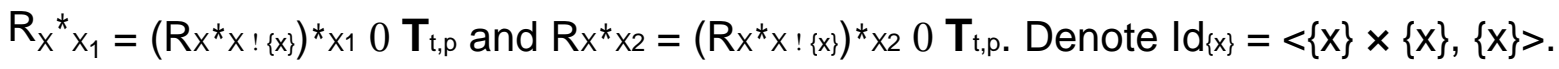

In view of lemma 3.5 we may distinguish three cases.

Case $1 \quad S 1 T=S 1 M=T 1 M=N$

Take $\mathrm{B}_{\mathrm{X}} 0 \mathrm{~V}^{\mathrm{n}}$ such that:

$$
\begin{array}{ll}
B_{X}(i)=\left(R_{X^{*} x_{1}}\right)+I_{\{x\}}+R_{X^{*} x 2} \quad \text { for all i 0 S 1 T, } \\
B_{X}(i)=I_{\{x\}}+\left(R_{X_{X}^{*}\{x\}}\right) \quad \text { for all i 0 T 1 M, and } \\
B_{X}(i)=\left(R_{X^{*} X\{x\}}\right)+I_{\{x\}} \quad \text { for all i 0 S 1 M. }
\end{array}
$$

Now since $S, M, T, N 0 B$ it follows straightforwardly that $F\left(B_{x}\right)=R_{x}$.

Case $2 \mathrm{~S} \chi \mathrm{T} \delta \mathrm{M}, \mathrm{S} 1 \mathrm{~T}=1$ and $\mathrm{S} \chi \mathrm{T} 0 \mathrm{~B}$.

Take $B_{X} 0 V^{n}$ such that:

$$
\begin{aligned}
& B_{X}(i)=\left(R_{X !\{x\}}\right)+I_{\{x\}} \quad \text { for } i 0 S \text {, } \\
& B_{X}(i)=I_{\{x\}}+\left(R_{X-\{x\}}\right) \quad \text { for i } 0 \mathrm{~T} \text {, and } \\
& \left.B_{x}(i)=R_{x}{ }^{\star} x_{2}+I_{\{x\}}+R x^{*} x 1 \text { for all i } 0 N \text { ! (S } \chi T\right) \text {. }
\end{aligned}
$$

Now since $S, T, S \chi T, N 0 B$ it follows straightforwardly that $F\left(B_{x}\right)=R_{x}$.

Case $3 \quad \mathrm{~S} 1 \mathrm{~T}=\mathrm{S} 1 \mathrm{M}=\mathrm{T} 1 \mathrm{M}=1$ and $\mathrm{S} \chi \mathrm{T} \chi \mathrm{M}=\mathrm{N}$.

We distinguish two subcases.

\section{Subcase $1 \quad p=0$.}

By baR $R_{x}$ denote $\left(R_{x} !\{<a, b>\}\right) \chi\{<b, a>\}$.

So, $R_{x}=x y R_{x}^{1}$, and $\operatorname{ld}_{\{y\}}+R_{x \star x !\{x, y\}}^{1}+\operatorname{ld}_{\{x\}}=R_{x}^{1}$.

Take $B_{x}$ such that

$$
\begin{aligned}
& I d_{\{y\}}+I_{\{x\}}+R_{X \star X !\{x, y\}}^{1}=B_{X}(i) \text { for i } 0 S, \\
& R_{X \star X !\{x, y\}}^{1}+I_{\{y\}}+I_{\{x\}}=B_{X}(i) \text { for i } 0 T \text {, and } \\
& \operatorname{ld}_{\{x\}}+R_{X \star X !\{x, y\}}^{1}+I_{\{y\}}=B_{X}(i) \text { for i } 0 M .
\end{aligned}
$$

Now by $S, T, M, N 0 B$ it follows that $F\left(B_{x}\right)=R_{x}$.

\section{Subcase 2 $\quad p \exists 1$.}

Then there are $a, b$, with $\{a, b\} \quad\{x, y\}$ such that $<a, b>0 R_{x}$ and $<b, a>0 R_{x}{ }^{1}$. Hence, 


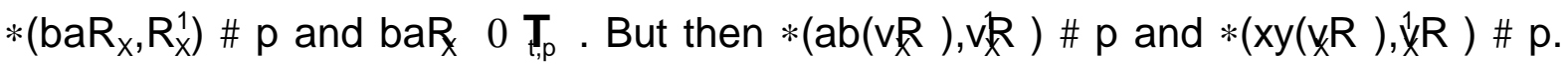

Furthermore, $*\left(\mathrm{ba}\left(\mathrm{yx} \mathrm{R}_{\mathrm{x}}\right), \mathrm{R}_{\mathrm{x}}^{1}\right)<\mathrm{p}$. So, $\mathrm{ba}\left(\mathrm{yx} \mathrm{R}_{\mathrm{x}}\right) 0 \mathbf{T}_{\mathrm{t}, \mathrm{p}}$.

Now consider $B_{X}$ such that

$$
\begin{aligned}
& a b\left(v R_{X}\right)=B_{X}(i) \text { for } i 0 S \\
& x y\left(v R_{Y}\right)=B_{x}(i) \text { for i } 0 T \\
& b a\left(y x R_{X}\right)=B_{X}(i) \text { for } i 0 M
\end{aligned}
$$

Now by $S, T, M 0 B$ it follows that $F\left(B_{x}\right)=R_{x}$.

\section{PROOF OF THEOREM 3.2}

Assume (3.3). We will deduce a contradiction.

Note that $\mathbf{T}_{m, 0}=\mathbf{L}$ for all $m,\{0,1,2, \ldots\}$. So, by a simple induction on $p$ and applying lemma 3.4 and lemma 3.6 it follows that $\mathbf{T}_{m, p} \phi \vee$ for all $m, p 0\{0,1,2, .$.$\} . Hence, \mathbf{T} \phi$ $\mathrm{U}\left\{\mathbf{T}_{\mathrm{m}, \mathrm{p}}: \mathrm{m}, \mathrm{p} 0\{0,1,2, .\}.\right\} \phi \mathrm{V}$. This contradicts $\mathrm{V} \delta \mathbf{T}$ which is assumed in (3.3). Hence, $\mathrm{F}$ is dictatorial.

An interpretation of this theorem has been discussed earlier. Let us reconsider this theorem theoretically here. Although no transitivity or acyclicity condition is imposed on the domain and the range of the welfare functions in theorem 3.2, both are imposed by other conditions. It is assumed that the range and the domain are in $\mathbf{T}$. So the relations in the range and the domain are complete, antisymmetric and reflexive. Especially for the range these conditions are restrictive, because they enforce a strict preference between all the alternatives. So, neither indifferences nor incomparabilities are possible under these restrictions.

Whether there exist stronger impossibility results, like theorem 3.2, in which the completeness and/or the antisymmetry is dropped is still an open question. The next and final theorem might invite the reader to deduce such stronger results.

\section{THEOREM 3.7}

Let $k$ be an arbitrary number such that $V=L=W_{0}, W_{1}, W_{2}, \ldots, W_{k} \phi \mathbf{R}$ are classified sets 
of orderings.

Furthermore, suppose $\mathrm{W}_{0} \delta_{\mathrm{m}} \mathrm{W}_{1} \delta_{\mathrm{m}} \ldots \delta_{\mathrm{m}} \mathrm{W}_{\mathrm{k}-1} \delta_{\mathrm{m}} \mathrm{F}\left(\mathrm{V}^{\mathrm{n}}\right)$.

Then $\mathrm{F}$ is dictatorial.

\section{PROOF OF THEOREM 3.7}

Suppose $F$ is non-dictatorial and such a k exists. Define $H: \mathbf{L} 6 \mathbf{C}$ for all $B_{A} 0 \mathbf{L}$ as follows $\mathrm{H}\left(\mathrm{B}_{\mathrm{A}}\right):=\operatorname{cav} \mathrm{F}\left(\mathrm{B}_{\mathrm{R}}\right)$. In $\mathrm{H}\left(\mathrm{B}_{\mathrm{R}}\right)$ all incomparabilities of $\mathrm{F}\left(\mathrm{B}_{\mathrm{A}}\right)$ have become indifferences. Because $\mathrm{F}$ is non-dictatorial $\mathrm{H}$ is non-dictatorial. Furthermore, it follows that $\mathrm{H}$ is neutral, independent of irrelevant alternatives and Pareto-optimal. Denote $W^{\text {cav }}:=\left\{\operatorname{cav}_{X}: R_{X} 0 W\right\}$.

Note that $\mathrm{M}\left(\mathrm{W} \chi\left\{\mathrm{R}_{\mathrm{x}}\right\}\right)^{\text {cav }}=\mathrm{M}\left(\mathrm{W}^{\text {cav }} \chi\left\{\operatorname{cav} \mathrm{R}_{\mathrm{x}}\right\}\right)$. So, $\mathrm{W}_{\mathrm{j}}^{\text {cav }}:=\mathrm{W}_{\mathrm{i}}^{\text {cav }}$ or $\mathrm{W}_{\mathrm{j}}^{\text {cav }} \delta_{\mathrm{m}} \mathrm{W}_{\mathrm{i}}^{\text {cav }}$, where $\mathrm{j}$ $=\mathrm{i}-1$.

Hence, there is a number $\mathrm{p}$ such that $\mathrm{V}=\mathbf{L}=\mathrm{C}_{0}, \mathrm{C}_{1}, \ldots \mathrm{C}_{\mathrm{p}} \phi \mathbf{C}$ are classified sets of orderings and $\mathrm{C}_{\mathrm{o}} \delta_{\mathrm{m}} \mathrm{C}_{1} \delta_{\mathrm{m}} \ldots \delta_{\mathrm{m}} \mathrm{C}_{\mathrm{p}-1} \delta_{\mathrm{m}} \mathrm{H}\left(\mathrm{V}^{\mathrm{n}}\right)$.

Now there are two cases.

Case 1 There is a relation $R_{x} 0 C_{p}-T$ which is irreducible and which cannot be condensated.

Because $R_{X}$ is irreducible and cannot be condensated there are $x_{1}, x_{2}, x_{3}, \ldots, x_{m} 0 X$ such that $* X^{\star}=m,<X_{1}, X_{2}>0 a R_{X}$ and $<x_{2}, x_{3}>,<x_{3}, x_{4}>, \ldots,<x_{m-1}, x_{m}>,<x_{m}, x_{1}>0 R_{x}$. Because $R_{X} 0 C_{p}=H\left(V^{n}\right)$, there is a profile $B_{X}$ $0 L^{n}$ such that $H\left(B_{X}\right)=R_{X}$.

Now take $A=\left\{a_{1}, a_{2}, \ldots, a_{p}, x_{1}\right\}$ and ${ }^{\star} A^{\star}=p+1$ and $A 1 X=\left\{x_{1}\right\}$.

Let $x_{1} a_{1} a_{2} \ldots a_{p}: R_{A}^{1} 0 L$.

Take $B_{Z}^{2} 0 L^{n}$ such that for i $0 \mathrm{~N} \mathrm{~B}_{Z}^{2}(i):=\operatorname{Sub}\left(B_{X}(i), x_{1}, R_{A}^{1}\right)$.

Then by using neutrality and Pareto-optimality $H\left(B_{Z}^{2}\right)=\operatorname{Sub}\left(R_{X}, x_{1}, R_{A}^{1}\right)=: R_{Z}^{3}$.

$\mathrm{R}_{\mathrm{Z}}^{3}$ is irreducible because $<\mathrm{x}_{1}, \mathrm{a}_{1}>,<\mathrm{a}_{1}, \mathrm{a}_{2}>, \ldots<\mathrm{a}_{\mathrm{p}-1}, \mathrm{a}_{\mathrm{p}}>0 \mathrm{aR}_{\mathrm{Z}}^{3}$ and $<\mathrm{a}_{\mathrm{p}}, \mathrm{x}_{2}>,<\mathrm{x}_{2}, \mathrm{x}_{3}>,<\mathrm{x}_{3}, \mathrm{x}_{4}>, \ldots,<\mathrm{x}_{\mathrm{m}}, \mathrm{x}_{1}>0 \mathrm{R}_{\mathrm{Z}}^{3}$.

$\mathrm{R}_{\mathrm{Z}}^{3}$ cannot be condensated because the elements in Z-X play different rôles.

Now applying theorem $2.6 \mathrm{p}$ times it follows that

$\mathrm{R}_{\mathrm{X}}=\mathrm{R}_{\mathrm{Z}}^{3 \star}{ }_{\mathrm{x}} 0 \mathrm{~W}_{0}=\mathrm{V}=\mathbf{L} \phi \mathbf{T}$.

This, however, cannot be the case.

Case 2 All irreducible relations $R_{x}$ in $C_{p}$ which cannot be condensated are in $\mathbf{T}$. 
Hence, for all $R_{A} 0 C_{p}$ there are equivalence classes ${ }_{1} B{ }_{2} B, \ldots, B$ of $E_{A} R$ ) such that $B_{1}, B_{2}, \ldots, B_{t}$ is a partition of $A$. And, furthermore, if $B=\{b, \ldots, b\}$ such that $b 0 B, b 0$ $B_{2}, \ldots, b_{t} 0 B_{t}$, then $R_{A}{ }^{*} B=T 1 C_{p}$.

Now we define $G: L^{n} 6 \mathbf{T}$ for all $B_{X} 0 L^{n}$ as follows $\mathrm{G}\left(\mathrm{B}_{\mathrm{x}}\right):=\mathrm{aH}\left(\mathrm{B}_{\mathrm{x}}\right) \chi\left(\mathrm{sH}\left(\mathrm{B}_{\mathrm{x}}\right) 1 \mathrm{~B}_{\mathrm{x}}(1)\right)$.

It is straightforward to prove that $G$ is neutral, independent of irrelevant alternatives, Pareto-optimal and non-dictatorial.

By theorem 3.2 it is sufficient to prove that $G\left(L^{n}\right) \phi C_{p}$.

Take $R_{A} 0 G\left(L^{n}\right)$. Then there are $R_{A}^{\prime} 0 C_{p}$ and profile $B_{A}^{\prime} 0 L^{n}$ such that $H\left(B_{A}^{\prime}\right)=R_{A}^{\prime}$ and $G\left(B_{A}^{\prime}\right)=R_{A}=a R_{A}^{\prime} \chi\left(s R_{A}^{\prime} 1 R_{A}^{\prime}(1)\right)$. Let $B, B_{2}, \ldots, B$ be the equivalence classes of $E\left(R^{\prime}\right)$. Take $B=\left\{b_{1}, b_{2}, \ldots, b_{t}\right\}$ such that $b_{1} 0 B_{1}, b_{2} 0 B_{2}, \ldots . b_{t} 0 B_{t}$. Then $H\left(B_{A}^{\prime{ }^{*}} B\right)=R_{A}^{\prime} \star_{B} 0 C_{p}$. Now let $\mathrm{B}_{\mathrm{A}_{0}}^{0}:=\mathrm{BA}^{*} \mathrm{~B}$ and $B_{A_{m}}^{m}(i):=\operatorname{Sub}\left(B_{A m-1}^{m-1}(i), b_{m}, B_{A}^{\prime}(i){ }^{*} B m\right)$ for all i $0 N$ and all $m 0\{1,2, \ldots, t\}$.

Then by the Pareto-optimality and the neutrality $G\left(B_{A}^{\prime}\right)^{\star} A_{m}=G(B A m)=H(B A m)$ for all $m 0$ $\{0,1, \ldots, t\}$.

Hence $R_{A}=G\left(B_{A}^{\prime}\right)^{\star}{ }_{A_{t}} 0 C_{p}$.

Note that the theorem above holds for all classifiable sets of relations $\mathrm{V} \phi \mathbf{T}$, such that for all $R_{X} 0 L$ and all $R_{Y} 0 V$ and all y $0 Y$ such that $X 1 Y \phi\{y\}$ : $\operatorname{Sub}\left(R_{Y}, y, R_{X}\right) 0 V$. So, $V$ is substitutionally closed over the set of linear orderings. So the question whether there exist stronger results than theorem 3.2 becomes interesting because by the partial result theorem 3.7 their abcense cannot be proven generally. 


\section{REFERENCES}

! Arrow K.J., 1963, Social choice and individual values, Yale University Press $\left(19^{\text {th }}\right.$ ed. $)$.

! Arrow K.J. \& M.D. Intriligator, 1986, Handbook of mathematical economics, vol III, Elsevier Science Publishers B.V., North-Holland.

! Black D., 1987, The theory of commities and elections, Kluwer Academic Publishers, $5^{\text {th }}$ ed., $1^{\text {st }}$ edition in 1958 by Cambridge University Press.

! Blair D.H. \& Pollack R.A., 1979, Collective rationality and dictatorship: The scope of the Arrow theorems, Journal of Economic Theory, 21, p.186 - 194.

! Blau D.H., 1957, The existence of a social welfare function, Econometrica, 25, p.302 $-313$.

! Blau D.H., 1979, Semiorders and collective choice, Journal of Economic Theory, 21, p.195 - 313.

! Condorcet, Caritat M. Marquis de, 1785, Essay sur l'application de l'analyse a la probabilité des descisions rendues à la pluralité des voix, Paris.

! Dodgson C.L., 1876, A method of taking votes on more than two issues, in Black (1987).

! Ferejohn J.A. \& Grether D., 1974, On a class of rational social decision procedures, Journal of Economic Theory, 8, p.471 - 482.

! Kelly J.S.,1978, Arrow impossibility theorems, New York, Academic Press.

! Kemeny J.G. \& J.L. Snell, 1962, Mathematical models in Social Sciences, New York, Ginn and Company. 
! Sen A.K., 1986, Social choice theory, In Arrow \& Intriligator, p.1073 - 1181.

! Storcken A., 1989, Possiblity Theorems for Social Welfare Functions, Tilburg University, disertation.

! Swart de H. and A. Storcken, 1992, Towards an Axiomatization of Orderings, Order, 9, p.367 - 396. 